\title{
Zabrinutost za oblik i tjelesnu težinu, suzdržavanje u prehrani i kognitivni obrasci hranjenja hrvatskih adolescenata
}

\section{/ Shape and Weight Concern, Dietary Restraint and Cognitive Eating Patterns in Croatian Adolescents}

\author{
Alessandra Pokrajac-Bulian', Simona Calugi'2, Petra Anić', \\ Miljana Kukić ${ }^{1}$, Tamara Mohorić ${ }^{1}$, Nataša Damjanić ${ }^{1}$ \\ ${ }^{1}$ Sveučilište u Rijeci, Filozofski fakultet, Odsjek za psihologiju, Rijeka, Hrvatska; ${ }^{2}$ Villa Garda Hospital, Odsjek za \\ poremećaje hranjenja i tjelesnu težinu, Verona, Italija \\ $/{ }^{1}$ University of Rijeka, Faculty of Humanities and Social Sciences, Department of Psychology, Rijeka, Croatia; ${ }^{2}$ Villa \\ Garda Hospital, Department of Eating and Weight Disorders, Verona, Italy \\ ORCID ID: https://orcid.org/0000-0001-9142-5781 (A. Pokrajac-Bulian) \\ ORCID ID: https://orcid.org/0000-0002-4028-1877 (S. Calugi) \\ ORCID ID: https://orcid.org/0000-0001-8841-5988 (P. Anić) \\ ORCID ID: https://orcid.org/0000-0002-1822-7807 (M. Kukić) \\ ORCID ID:https://orcid.org/0000-0002-5274-1850 (T. Mohorić)
}

\begin{abstract}
Cilj je ovoga istraživanja bio ispitati simptomatologiju poremećaja hranjenja i njezin odnos s kognitivnim obrascima hranjenja, indeksom tjelesne mase (ITM) i spolom u hrvatskih adolescenata. Istraživanjem je obuhvaćen 649 sudionika, od čega je 50,4\% bilo mladića. Svi sudionici bili su učenici prvih razreda srednjih škola u dobi od 14 do 16,5 godina, koji su popunjavali upitnike u školskim ambulantama tijekom redovnog zdravstvenog pregleda. Adolescentice su pokazale više simptoma poremećaja hranjenja i češću uporabu kognitivnih obrazaca hranjenja u usporedbi s adolescentima. Nadalje, adolescenti s većim ITM-om također su izvijestili o više simptoma poremećaja hranjenja i kognitivnoga suzdržavanja. Zaključno, kognitivni obrasci hranjenja i povezana psihopatologija poremećaja hranjenja relevantne su karakteristike hrvatskih adolescenata, uglavnom kod djevojaka s višim ITM-om.

I The aim of this study was to examine eating disorder symptomatology and its relationship with cognitive eating patterns, body mass index (BMI) and sex in Croatian adolescents. This study included 649 participants, of which $50.4 \%$ were boys. All of the participants were first-grade high school students with ages ranging from 14 to 16.5 years who completed the questionnaires in the medical centre during their regular health examination. Female adolescents showed more eating disorder symptoms and more frequent use of cognitive eating patterns than male adolescents. Additionally, adolescents with a higher BMI also reported more eating disorder symptoms and cognitive restraint. In conclusion, cognitive eating patterns and associated eating disorder psychopathology are relevant features in Croatian adolescents, mainly among female subjects with a higher BMI.
\end{abstract}

\section{ADRESA ZA DOPISIVANJE / CORRESPONDENCE:}

Prof. dr. sc. Alessandra Pokrajac-Bulian Sveučilište u Rijeci, Filozofski fakultet Odsjek za psihologiju Sveučilišna avenija 4 51000 Rijeka, Hrvatska E-pošta: pokrajac@ffri.uniri.hr

\section{KLJUČNE RIJEČI / KEY WORDS:}

Poremećaji hranjenja / Eating Disorders Kognitivni obrasci hranjenja / Cognitive Eating Patterns Indeks tjelesne mase / Body Mass Index Adolescenti / Adolescents 


\section{UVOD}

Poremećaji hranjenja i kontrola tjelesne mase uobičajena su ponašanja kod adolescenata različitih etničkih i sociodemografskih skupina (1). Pretjerano naglašavanje mršavosti u većini socijalnih sredina čini se čimbenikom koji u većoj mjeri pridonosi porastu prevalencije odstupajućih ponašanja i navika hranjenja (2). S druge strane, porast raširenosti pretilosti i njezinih zdravstvenih posljedica također je povezan sa zabrinutošću za težinu i oblik tijela, što nadalje dovodi do vrlo problematičnih ponašanja vezanih uz hranjenje (3).

Pritisak na mršavost puno je veći za žene negoli za muškarce, a percipirana idealna slika tijela postaje progresivno sve sitnija, dok trenutna prosječna tjelesna masa postaje sve viša, a pokušaji smanjenja tjelesne mase sve učestaliji (4). Opisana dinamika svakako pridonosi porastu raširenosti poremećaja hranjenja kod mladih žena i osoba koje su prekomjerno teške. Godine 2018., prosječno je, gotovo $20 \%$ petnaestogodišnjaka u zemljama EU bilo preuhranjeno ili pretilo, što predstavlja značajan porast u odnosu na podatke iz 2010. godine (5). Istraživanje iz 2008. godine pokazuje da se $27,5 \%$ adolescenata $u$ Hrvatskoj procjenjuje "previše debelima", a taj postotak raste s dobi tako da se na taj način procjenjuje 38,9\% petnaestogodišnjakinja i 16,6 \% petnaestogodišnjaka (6). Istraživanje objavljeno 2020. godine, koje je uključivalo 26 zemalja EU, pokazalo je da od 2002. do 2014. godine postoji značajan porast ponašanja usmjerenih na redukciju tjelesne težine kod adolescenata oba spola u Hrvatskoj (7) te je zabilježen značajan porast tih ponašanja sa $6,2 \%$ na $11,9 \%$, posebno kod adolescenata višega ITM-a. Istraživanja na hrvatskim adolescentima češće se provode u sklopu komparativnih studija koje uključuju druge EU zemlje ili SAD, te se pretežito bave prevalencijom preuhranjenosti i pretilosti, dok istraživanja o simptomima poremećaja hranjenja u hrvatskih adolescenata, nisu tako česta.

Slijedom navedenoga, cilj je ovoga istraživanja procijeniti psihopatologiju poremećaja hranje-

\section{INTRODUCTION}

Disordered eating and weight-control behaviours are common among adolescents in ethnically and socioeconomically diverse samples (1). The excessive emphasis on thinness in most societies seems to be a major contributing factor to the increased prevalence of disordered eating attitudes and behaviours (2). On the other hand, the increase in obesity and its health consequences is also related to weight and shape concerns that, in turn, can produce problematic eating behaviours (3).

For women, the social pressure to be thin is higher than for men, and the perceived ideal body image has become progressively smaller while the actual mean body size has progressively become larger, and attempts to lose weight have increased (4). Such a dynamic might contribute to the increase in disordered eating among young women and individuals who are overweight. In 2018, on average, almost $20 \%$ of 15 -year-olds were either overweight or obese across EU countries, which was an increase compared to 2010 (5). A survey conducted in 2008 shows that $27.5 \%$ of adolescents in Croatia evaluated themselves as "too fat", and this percentage increases with age, with $38.9 \%$ of 15 -year-old girls and $16.6 \%$ of 15 -year-old boys are self-assessing in this way (6). A study published in 2020, which included 26 EU countries, showed that in Croatia between 2002 and 2014 there was a significant increase in behaviours aimed at weight reduction in adolescents of both sexes (7) with an increase from $6.2 \%$ to $11.9 \%$ especially visible in adolescents of higher BMI. Research on Croatian adolescents is more often conducted as part of comparative studies involving other EU countries or the United States, and mainly deals with the prevalence of overweight and obesity, while research on of eating disorder symptoms is less common.

Thus, the aim of this study was to assess eating disorder psychopathology and eating pat- 
nja i obrasce hranjenja te ispitati povezanost ovih značajki s indeksom tjelesne mase (ITM) i spolom u hrvatskih adolescenata, polaznika prvih razreda srednje škole.

\section{METODA}

\section{Sudionici i postupak}

Adolescenti $(N=649)$, od kojih 321 djevojka $(49,5 \%)$ i 328 mladića $(50,40 \%)$ ispunili su niz upitnika tijekom redovitih sistematskih (preventivnih) pregleda koje svake godine organizira $\mathrm{Na}-$ stavni zavod za javno zdravstvo Primorsko-goranske županije (PGŽ) za učenike prvih razreda srednjih škola. Učenici su prosječne dobi 15 godina ( $S D=0,32$, raspona 14 do 16,5 godina). Tijekom zdravstvenih pregleda izmjerena je visina i težina učenika, te je izračunat indeks tjelesne mase [ITM - težina $(\mathrm{kg}) / \mathrm{visina}(\mathrm{m})^{2}$ ]. Istraživanje je provedeno u razdoblju prije javljanja pandemije COVID-19, od veljače do ožujka 2020. godine.

Prije liječničkog pregleda, učenici su obavili kraći razgovor s liječnikom školske medicine, te su prikupljene sljedeće informacije: uzimanje lijekova, ranija psihoterapija, kronične bolesti te provođenje dijete u cilju smanjenja tjelesne mase. Svi učenici koji su pristupili sistematskom (preventivnom) pregledu ispunili su ponuđene upitnike. Osim što su učenici za sudjelovanje u istraživanju dali svoj pristanak, o istraživanju su roditelji, ravnatelji i nastavnici informirani pismom koje je upućeno na adrese svih srednjih škola u Primorsko-goranskoj županiji.

\section{Mjerni instrumenti}

Upitnik simptoma poremećaja hranjenja (Eating Disorder Examination Questionnaire - EDE-Q, verzija 6.0) korišten je u ovom istraživanju za procjenu mogućih psihopatoloških ponašanja i simptoma poremećaja hranjenja u posljednjih 28 dana (8). Upitnik uključuje četiri različite podljestvice: Suzdržavanje, Zabrinutost za hra- terns and to examine the relationship between these features and body mass index (BMI) and gender in Croatian adolescents attending firstgrade high school.

\section{METHODS}

\section{Participants and Procedure}

Adolescents $(N=649)$, of which 321 girls (49.5\%), and 328 boys (50.40\%) completed questionnaires during regular preventive health examinations organized by the Institute of Public Health of Primorje-Gorski Kotar County (PGKC) every year and included first-grade high school students. They were mean age of 15 years ( $S D=0.32$, range 14 to 16.5 years). The height and weight of the students were measured during the examination, and the body mass index was calculated [BMI; weight $(\mathrm{kg}) /$ height $(\mathrm{m})^{2}$ ]. The study was conducted in the period prior to the COVID-19 pandemic, from February to March 2020.

Prior to the medical examination, the students had a short conversation with the school doctor, and the following information was collected: taking medications, previous psychotherapy, chronic illness, and dieting for weight loss. All students who approached the medical (preventive) examination, filled in the offered questionnaires. In addition to the students' consent to participate in the research, parents, school principals and teachers were informed about the research by a letter sent to all high schools in the Primorje-Gorski Kotar County.

\section{Instruments}

The Eating Disorder Examination Questionnaire (EDE-Q) version 6.0 was used in this study to assess possible eating disorder psychopathology and behaviours in the participants over the previous 28 days (8). The measure provides four attitudinal subscale scores: $R e$ - 
njenje, Zabrinutost za težinu te Zabrinutost za oblik tijela. Ukupni rezultat dobiva se zbrajanjem rezultata svih podljestvica i dijeljenjem dobivene vrijednosti brojem podljestvica (četiri). Sudionici procjenjuju učestalost ili težinu kognitivnih, afektivnih i ponašajnih karakteristika na ordinalnoj ljestvici od 7 stupnjeva $(0=$ niti jedan dan $-6=$ svaki dan; $0=$ niti jednom -6 svaki put ili $0=$ uopće ne $-6=$ značajno). Šest preostalih čestica, koje ne čine podljestvice, mjeri učestalost specifičnih ponašanja. Posebno se sudionici pitaju o broju dana ili epizoda u kojima su doživjeli objektivna prejedanja uz gubitak kontrole, imali samoizazvana povraćanja, zlorabljali laksative i/ili pretjerano vježbali. U našem je uzorku Cronbach alfa zadovoljavajući za sve četiri podljestvice i za ukupan rezultat na upitniku, te se kreće u rasponu od .75 do .94 .

Hrvatska verzija Trofaktorskog upitnika obrazaca hranjenja (Three-Factor Eating Questionnaire - TFEQ-R18) sadrži 18 čestica koje čine tri podljestvice, te ispituje: Kognitivno suzdržavanje, Nekontrolirano jedenje i Emocionalno jedenje $(9,10)$. Podljestvica Kognitivno suzdržavanje odnosi se na kontinuirano i potpuno suzdržavanje od hranjenja umjesto korištenja osjećaja sitosti i gladi u njegovoj regulaciji, a u cilju kontrole težine. Podljestvica Nekontrolirano jedenje mjeri sklonost k prejedanju uz osjećaj gubitka kontrole nad hranom, dok se Emocionalno jedenje odnosi na tendenciju k jedenju zbog doživljavanja negativnih emocija. Na našem je uzorku pouzdanost zadovoljavajuća, te se kreće u rasponu od .75 do .83 .

\section{Statističke analize}

Podatci su prikazani kao prosječne vrijednosti i standardne devijacije (SD) ili kao brojevi i postotci ako je to primjerenije. Kako bi se usporedile spolne razlike korišten je t-test za nezavisne varijable. Povrh toga, odnos između ITM-a, EDE-Q-a i TFEQ-R18 provjeren je korištenjem Pearsonovog koeficijenta korelacije, posebno za mladiće i djevojke. Kako bi se provjerilo postojanje razlika straint, Eating Concern, Shape Concern, and

Weight Concern. An overall global score is expressed as the mean of the four subscale scores. Participants estimate the frequency or severity of specific cognitive, affective, and behavioural characteristics on a 7-point ordinal response $(0=$ no days $-6=$ every day; $0=$ none of the time -6 every time; or $0=$ not at all -6 $=$ markedly) scale. The 6 remaining items measure the frequency of specific behaviours. In particular, the participants were asked to provide the number of days or episodes in which they had experienced overeating, objective binge eating, self-induced vomiting, laxative misuse, and/or excessive exercising. In our sample, Cronbach's alphas were satisfactory for all subscales and the total score, ranging from .75 to .94 .

The Croatian version of the Three-Factor Eating Questionnaire (TFEQ-R18), containing 18 items divided into 3 subscales, examining cognitive restraint, uncontrolled eating, and emotional eating, was used $(9,10)$. The Cognitive restraint subscale of the latter refers to the constant and global restraint from eating instead of using hunger and satiety as eating regulators, as the goal of such behaviour is weight control. The Uncontrolled eating subscale measures tendencies to overeat with a sense of loss of control, while Emotional eating refers to the tendency to eat in response to negative emotions. In our sample, the reliability was satisfactory and ranged from .75 to .83 .

\section{Statistical analysis}

Data are presented as the mean and standard deviation $(S D)$ or as numbers and percentages, as appropriate. A t-test for independent variables was used to compare gender differences. Moreover, the relationship between BMI, EDE-Q and TFEQ-R18 was examined using Pearson correlation coefficients separately for boys and girls. To examine whether there were differences in the measured variables depend- 
$\mathrm{u}$ ispitanim varijablama s obzirom na tjelesnu masu sudionika (pothranjenost, normalna tjelesna masa, preuhranjenost i pretilost) korištena je analiza varijance (ANOVA) uz kontrolu spola.

\section{REZULTATI}

Prosječan ITM sudionika iznosi 22,49 (SD = $4,38)$, u rasponu od 12,38 do 47,59. U uzorku je 2,5 \%, 74,9 \%, 11,7 \% i 10,9 \% sudionika klasificirano redom kao pothranjeno, normalne tjelesne mase, preuhranjeno i pretilo. Većina je adolescenata normalne težine, ali je relativno visok postotak mladića i djevojaka koji su preuhranjeni ili pretili. Oko $23 \%$ djevojaka i $22 \%$ mladića ima prekomjernu tjelesnu masu.

Teorijski raspon pubertalnog statusa sudionika kreće se od 1 (nije razvijen) do 5 (potpuno razvijen). Prosječna je vrijednost 4,69 (medijan i mod = 5). U uzorku je redom $0.5 \%, 30.1 \%$ i $69.4 \%$ sudionika klasificirano u 3., 4. i 5. pubertalni stadij. Prosječna dob javljanja menarhe u uzorku djevojaka iznosi 12,53 godina $(S D=1,25)$. Osim toga, jedna od djevojaka u uzorku navodi trenutno korištenje oralne kontracepcije.

Analizom dodatnih karakteristika sudionika utvrdili smo da 3 sudionika izvještavaju o ranijem psihoterapijskom tretmanu zbog poremećaja hranjenja; 30 ih navodi kroničnu bolest (4 dijabetes i 26 ostale bolesti $=4,6 \%$ ); 4 navodi korištenje farmakoterapije koja može izazvati porast tjelesne mase ( $0,6 \%)$; dok 32 aktivno provodi dijetu u cilju smanjenja tjelesne mase (4.9\%).

Spolne razlike pokazuju da su EDE-Q i TFEQ-R18 podljestvice te ukupan rezultat na upitnicima viši u uzorku djevojaka nego mladića (tablica 1).

Korelacijske analize pokazuju umjerenu povezanost ITM-a i kognitivnog suzdržavanja iz TFEQ-R18 upitnika u oba uzorka. Korelacije emocionalnoga jedenja i nekontroliranoga jedenja iz TFEQ-18 upitnika s ITM-om različite su za mladiće i djevojke. Naime, na uzorku mladića ing on the weight of the participants (underweight, normal weight, overweight and obesity), we also performed an analysis of variance (ANOVA) controlling for gender.

\section{RESULTS}

The average BMI was $22.49(S D=4.38)$, ranging from 12.38 to 47.59 . In the sample, $2.5 \%$, $74.9 \%, 11.7 \%$, and $10.9 \%$ of participants were classified as underweight, normal weight, overweight, and obese, respectively. Most adolescents had a normal weight, but a relatively large percentage of both boys and girls were either overweight or obese. Approximately 23\% of girls and $22 \%$ of boys were classified as having excess body weight.

The theoretical range of the pubertal status of participants ranges from 1 (not developed) to 5 (fully developed). The mean value was estimated at 4.69 (median and mode $=5$ ). There were $0.5 \%, 30.1 \%$, and $69.4 \%$ of participants classified as stage 3, 4 and 5, respectively. The mean age of menarche onset in the female sample was 12.53 years $(S D=1.25)$. Moreover, one girl reported currently taking an oral birth control pill.

When we analysed the additional characteristics, we found that 3 participants reported previously undergoing psychotherapy for an eating disorder; 30 reported a chronic illness ( 4 diabetes and 26 other illnesses $=4.6 \%$ ); 4 reported pharmacological therapies that could cause weight gain $(0.6 \%)$; and 32 were dieting trying to induce a weight loss (4.9\%).

Gender differences indicated that the EDE-Q and TFEQ-R18 subscale and global scores were significantly higher in the female sample than in the male sample (Table 1).

Correlation analysis showed that BMI and TFEQ-R18 cognitive restraint were moderately correlated in both subsamples. TFEQ-R18 emotional eating and uncontrolled eating had 
TABLICA 1. Spolne razlike u TFEQ-R18 i EDE-Q, ukupni rezultat i rezultati na podljestvicama

TABLE 1. Gender Differences in TFEQ-R18 and EDE-Q, global and subscale scores

\begin{tabular}{|c|c|c|c|c|c|c|c|}
\hline & \multicolumn{2}{|c|}{$\begin{array}{l}\text { Ukupni uzorak / } \\
\text { Whole sample }\end{array}$} & \multicolumn{2}{|c|}{$\begin{array}{l}\text { Djevojke I } \\
\text { Females }\end{array}$} & \multicolumn{2}{|c|}{ Mladići / Males } & \multirow[t]{2}{*}{$t$} \\
\hline & $M$ & $S D$ & $M$ & $S D$ & $M$ & $S D$ & \\
\hline $\begin{array}{l}\text { Emocionalno jedenje - TFEQ-R18 / Emotional Eating - } \\
\text { TFEQ-R18 }\end{array}$ & 1.40 & 0.64 & 1.58 & 0.75 & 1.23 & 0.44 & $7.02^{* *}$ \\
\hline $\begin{array}{l}\text { Nekontrolirano jedenje - TFEQ-R18 / Uncontrolled Eating - } \\
\text { TFEQ-R18 }\end{array}$ & 1.69 & 0.56 & 1.77 & 0.60 & 1.62 & 0.50 & $3.20^{* *}$ \\
\hline $\begin{array}{l}\text { Kognitivno suzdržavanje - TFEQ-R18 / Cognitive Restraint } \\
\text {-TFEQ-R18 }\end{array}$ & 1.89 & 0.79 & 1.69 & 0.68 & 1.58 & 0.59 & $2.14^{*}$ \\
\hline Suzdržavanje - EDE-Q / Restraint - EDE-Q & 0.82 & 1.19 & 0.95 & 1.32 & 0.70 & 1.01 & $2.66^{* *}$ \\
\hline Zabrinutost za hranjenje - EDE-Q / Eating Concern - EDE-Q & 0.45 & 0.80 & 0.60 & 0.94 & 0.31 & 0.58 & $4.75^{* *}$ \\
\hline Zabrinutost za oblik tijela - EDE-Q / Shape Concern - EDE-Q & 1.28 & 1.40 & 1.72 & 1.58 & 0.85 & 1.05 & $8.01^{* *}$ \\
\hline Zabrinutost za težinu - EDE-Q / Weight Concern - EDE-Q & 1.05 & 1.30 & 1.41 & 1.49 & 0.70 & 0.94 & $7.32 * *$ \\
\hline EDE-Q - Ukupni rezultat / EDE-Q - Global score & 0.95 & 1.09 & 1.15 & 1.15 & 0.64 & 0.76 & $6.57^{* *}$ \\
\hline \multicolumn{8}{|c|}{ Upitnik simptoma poremećaja hranjenja, $n(\%)$ ako je dostupno / Eating Disorder Examination Questionnaire, $\mathrm{n}(\%)$ if present } \\
\hline $\begin{array}{l}\text { Epizode objektivnoga prejedanja / Objective binge eating } \\
\text { episodes }\end{array}$ & $150(23.5 \%)$ & & $85(26.8 \%)$ & & $64(20 \%)$ & & \\
\hline Samoizazvano povraćanje / Self-induced vomiting & $32(5.0 \%)$ & & $16(5.0 \%)$ & & $16(4.9 \%)$ & & \\
\hline Zlouporaba laksativa / Laxative misuse & $24(3.7 \%)$ & & $9(2.8 \%)$ & & $15(4.6 \%)$ & & \\
\hline Pretjerano vježbanje / Excessive exercise & $160(25.2 \%)$ & & $75(25.5 \%)$ & & $85(26.6 \%)$ & & \\
\hline
\end{tabular}

Bilješka. TFEQ-R18: Trofaktorski upitnik obrazaca hranjenja; EDE-Q: Upitnik simptoma poremećaja hranjenja / Note. TFEQ-R18: Three-Factor Eating Questionnaire; EDE-Q: Eating Disorder Examination Questionnaire

${ }^{*} \mathrm{p}<.05,{ }^{* *} \mathrm{p}<.01$

nismo dobili povezanost između ITM-a i nekontroliranoga jedenja, dok je korelacija u djevojaka negativna i niska, iako statistički značajna $(r$ $=-.13, p<.05)$, dok emocionalno jedenje i ITM nisu u korelaciji kod djevojaka, a kod mladića su u značajnoj pozitivnoj, iako niskoj korelaciji $(r=.14, p<.05)$. Korelacijski obrasci za kognitivno hranjenje mjereno upitnikom TFEQ-R18 i rezultati dobiveni na EDE-Q (na pojedinim podljestvicama i ukupnom rezultatu) jednaki su za oba spola, osim što je emocionalno jedenje iz TFEQ-R18 snažnije povezano sa zabrinutošću za hranjenje iz EDE-Q, dok je kognitivno suzdržavanje iz TFEQ-R18 snažnije povezano sa zabrinutošću za oblik tijela iz EDE-Q (tablica 2).

Usporedbom adolescenata različite uhranjenosti (isključili smo kategoriju pothranjenih s obzirom da je sadržavala mali broj sudionika) dobiveno je da se skupine međusobno značajno razlikuju u suzdržavanju iz EDE-Q upitnika $(F(2,606)=$ $\left.21,62, p<.01 ; \eta^{2}=.07\right)$. Korištenjem SNK post different correlation patterns with respect to BMI for boys and girls. In fact, we found no correlation between BMI and uncontrolled eating in boys and a significant negative but low correlation coefficient $(r=-.13, p<.05)$ in girls, whereas emotional eating and BMI were not correlated in girls, but in boys, we obtained a significant, positive, and low correlation $(r=.14, p<.05)$. The pattern of correlations of TFEQ-R18 cognitive eating and EDE-Q (subscales and global score) was the same for both genders, with TFEQ-R18 emotional eating strongly related to EDE-Q eating concerns and TFEQ-R18 cognitive restraint with EDE-Q shape concern (Table 2).

The comparison among weight categories (excluding the underweight category that had a very small number of respondents) indicated that the groups differed significantly in EDE-Q restraint $\left(F(2,606)=21.62, p<.01 ; \eta^{2}=.07\right)$. Based on the SNK post hoc test, we found that 
TABLICA 2. Pearsonovi koeficijenti korelacije mjerenih varijabli za mladiće (iznad dijagonale) i djevojke (ispod dijagonale) TABLE 2. Pearson Correlation Coefficients of the Measured Variables for males (upper part) and females (lower part)

\begin{tabular}{|c|c|c|c|c|c|c|c|c|c|c|c|}
\hline & & 1. & 2. & 3. & 4. & 5. & 6. & 7. & 8. & 9. & 10 \\
\hline 1. & Dob / Age & - & -.04 & .09 & .02 & -.01 & .01 & .08 & -.01 & -.02 & .04 \\
\hline 2. & ITM / BMI & -.02 & - & $.14^{*}$ & -.03 & $.39 * *$ & $.39 * *$ & $.28^{* *}$ & $.43^{* *}$ & $.43^{* *}$ & $.49 * *$ \\
\hline 3. & $\begin{array}{l}\text { Emocionalno jedenje - TFEQ-R18 / Emotional } \\
\text { Eating - TFEQ-R18 }\end{array}$ & -.05 & .02 & - & $.36^{* *}$ & $.19^{* *}$ & $.16^{* *}$ & $.40^{* *}$ & $.29 * *$ & $.28^{* *}$ & $.30^{* *}$ \\
\hline 4. & $\begin{array}{l}\text { Nekontrolirano jedenje - TFEQ-R18 / Uncon- } \\
\text { trolled Eating - TFEQ-R18 }\end{array}$ & $-.12^{*}$ & $-.13^{*}$ & $.57^{* *}$ & - & .05 & .01 & $.26^{* *}$ & $.17^{* *}$ & $.13^{*}$ & $.13^{* *}$ \\
\hline 5. & $\begin{array}{l}\text { Kognitivno suzdržavanje - TFEQ-R18 / Cogni- } \\
\text { tive Restraint - TFEQ-R18 }\end{array}$ & .00 & $.26^{* *}$ & .01 & $.13^{*}$ & - & $.64^{* *}$ & $.32^{* *}$ & $.48^{* *}$ & $.53^{* *}$ & $.60^{* *}$ \\
\hline 6. & Suzdržavanje - EDE-Q / Restraint - EDE-Q & .04 & $.25^{* *}$ & $.15^{*}$ & .08 & $.73^{* *}$ & - & $.44^{* *}$ & $.54^{* *}$ & $.57^{* *}$ & $.75^{* *}$ \\
\hline 7. & $\begin{array}{l}\text { Zabrinutost za hranjenje - EDE-Q / Eating } \\
\text { Concern - EDE-Q }\end{array}$ & $-.14^{*}$ & $.13^{*}$ & $.41^{* *}$ & $.37^{* *}$ & $.49^{* *}$ & $.59^{* *}$ & - & $.60^{* *}$ & $.59^{* *}$ & $.72^{* *}$ \\
\hline 8. & $\begin{array}{l}\text { Zabrinutost za oblik tijela - EDE-Q / Shape } \\
\text { Concern - EDE-Q }\end{array}$ & .01 & $.35^{* *}$ & $.35^{* *}$ & $.26^{* *}$ & $.56^{* *}$ & $.60^{* *}$ & $.67^{* *}$ & - & $.88^{* *}$ & $.93^{* *}$ \\
\hline 9. & $\begin{array}{l}\text { Zabrinutost za težinu - EDE-Q / Weight Concern } \\
\text { - EDE-Q }\end{array}$ & -.05 & $.37^{* *}$ & $.31^{* *}$ & $.22^{* *}$ & $.56^{* *}$ & $.61^{* *}$ & $.69^{* *}$ & $.91^{* *}$ & - & $.92^{* *}$ \\
\hline 10. & EDE-Q - Ukupni rezultat / EDE-Q -Global score & -.04 & $.37^{*}$ & $.32^{* *}$ & $.24^{* *}$ & $.66^{* *}$ & $.78^{* *}$ & $.80^{* *}$ & $.95^{* *}$ & $.94^{* *}$ & - \\
\hline
\end{tabular}

Bilješka. ITM: Indeks tjelesne mase; TFEQ-R18: Trofaktorski upitnik obrazaca hranjenja; EDE-Q: Upitnik simptoma poremećaja hranjenja / Note. BMI: Body Mass Index TFEQ-R18: Three-Factor Eating Questionnaire; EDE-Q: Eating Disorder Examination Questionnaire

${ }^{*} \mathrm{p}<.05,{ }^{* *} \mathrm{p}<.01$.

hoc testa, pronašli smo da sudionici koji su preuhranjeni $(\mathrm{AS}=1,32)$ i pretili $(\mathrm{AS}=1,43)$ imaju na toj varijabli više rezultate u odnosu na one normalne tjelesne mase (AS=0.66). Osim toga, adolescenti s pretilošću $(A S=0,75)$ imaju značajno viši rezultat na podljestvici zabrinutosti za hranjenje iz EDE-Q upitnika $(F(2,599)=7.50, p<$ $\left..01 ; \eta^{2}=.02\right)$ u usporedbi sa sudionicima normalne tjelesne mase $(\mathrm{AS}=0,39)$. Nadalje, adolescenti s pretilošću $(A S=2,02$ u odnosu prema $A S=1,59$ za preuhranjene i $\mathrm{AS}=0,83$ za one normalne težine) imaju najviši rezultat na EDE-Q podljestvici zabrinutosti za težinu $(F(2,588)=34.43, p<.01$; $\left.\eta^{2}=.10\right)$. Također i kod zabrinutosti za oblik tijela $\left(F(2,584)=30.74, p<.01 ; \eta^{2}=.10\right)$ adolescenti s pretilošću imaju najviše rezultate (AS=2,26), a prate ih preuhranjeni adolescenti $(\mathrm{AS}=1,86)$ te oni normalne tjelesne mase ( $\mathrm{AS}=1, .06)$. Konačno, dobiven je i zanimljiv rezultat u vezi kognitivnog suzdržavanja iz TFEQ-R18 koji je značajno niži u adolescenata normalne tjelesne mase (AS $=1,77)$ u usporedbi s adolescentima koji su preuhranjeni (AS=2,28) i pretili (AS=2,29) $(F(2$, $\left.586)=24,01, p<.01 ; \eta^{2}=.08\right)$, dok za ostale dvije podljestvice nisu dobivene razlike. subjects with overweight (AS=1.32) and obesity (AS=1.43) had significantly higher scores than normal weight subjects on this variable $(\mathrm{AS}=0.66)$. Moreover, adolescents with obesity (AS=0.75) had a significantly higher score on the EDE-Q eating concerns subscale ( $F(2$, 599) $\left.=7.50, p<.01 \eta^{2}=.02\right)$ than participants with a normal weight (AS=0.39). Furthermore, adolescents with obesity ( $\mathrm{AS}=2.02$ in comparison to AS = 1.59 for overweight, and AS = 0.83 for those of normal weight) had the highest score for the EDE-Q weight concern ( $F(2$, $\left.588)=34.43, p<.01 ; \eta^{2}=.10\right)$. Additionally, in regard of body shape concerns $(F(2,584)=$ $30.74, \mathrm{p}<.01 ; \eta 2=.10$ ), adolescents with obesity have the highest scores (AS $=2.26$ ), followed by overweight adolescents $(\mathrm{AS}=1.86)$, and those of normal body weight (AS = 1.06). Finally, TFEQ-R18 cognitive restraint was significantly lower in adolescents with a normal body weight $(A S=1.77)$ than in those with overweight ( $\mathrm{AS}=2.28)$ and obesity ( $\mathrm{AS}=2.29$ ) $\left(F(2,586)=24.01, p<.01 ; \eta^{2}=.08\right)$, while on the remaining two subscales, there were no differences. 


\section{RASPRAVA}

Cilj je ovoga istraživanja bio ispitati odstupajuća ponašanja i psihopatologiju poremećaja hranjenja kod učenika prvih razreda različitih srednjih škola u PGŽ-u te ispitati kakvi su obrasci hranjenja u mladića i djevojaka s obzirom na njihovu različitu tjelesnu masu. Dobivena su tri glavna nalaza. Prvi je nalaz da je oko $25 \%$ srednjoškolaca u prvim razredima u PGŽ-u preuhranjeno ili pretilo, podatak koji je u skladu $s$ ranije dobivenim rezultatima istraživanja $s$ adolescentima u različitim zemljama EU (11), dok je tek 2,5\% ( $\mathrm{N}=16)$ adolescenata neuhranjeno, zbog čega je ova skupina izostavljena iz daljnjih analiza, no tome bi se svakako trebalo detaljnije posvetiti u budućim istraživanjima.

Drugo, pronašli smo da djevojke značajno češće koriste kognitivne obrasce hranjenja. Adolescentice su sklonije ograničavati unos hrane te se češce hraniti pod utjecajem emocionalnih čimbenika u odnosu na mladiće. Neka istraživanja pokazuju da mlade djevojke koje provode visoko restriktivne dijete u kombinaciji s drugim obrascima hranjenja, poput dezinhibicije, češće doživljavaju neuspjeh u svojim naporima suzdržavanja od hrane te u konačnici imaju više odstupajućih ponašanja u vezi hranjenja, poput primjerice, prejedanja (12). Ako ovim nalazima pridodamo činjenicu da se u tim trenutcima gubitka kontrole češće konzumira visoko kalorična hrana, onda dobiveni nalaz može ukazati na postojanje povećanog rizika u djevojaka za razvoj preuhranjenosti i pretilosti u budućnosti (13). Povrh toga, osobe koje se s negativnim emocijama suočavaju s povećavanjem unosa hrane mogu, kasnije, razviti i veći broj simptoma poremećaja hranjenja (14). Djevojke su sklonije ograničavanju veličine svojih porcija te češće jedu manje od onoga koliko bi uistinu željele pojesti. Ovi rezultati stoga ne iznenađuju ako uzmemo u obzir činjenicu da su djevojke izloženije visokoj razini socijalnoga pritiska na mršavost te na pritisak okoline u vezi očekivanog idealnoga izgleda tijela (vitkoga, mršavoga

\section{DISCUSSION}

This study aimed to assess eating disorder psychopathology and behaviours in first-grade high school students in PGKC and to evaluate the relationship with eating patterns in both male and female participants and at different levels of body weight. There were three main findings. First, we found that approximately $25 \%$ of first-grade high school students in PGKC are overweight or obese, confirming previous studies of students across EU countries (11), while only $2.5 \%(\mathrm{~N}=16)$ of adolescents were underweight, which is why this group was left out of further analyses, but this should certainly be addressed in more detail in future research.

Second, we found that girls were significantly more likely to use cognitive eating patterns. Girls were more inclined to limit their food intake and have their diet affected by emotional factors than boys. It was shown in some research that young girls with high dietary restraint in combination with other eating behaviours, specifically disinhibition, were more likely to fail at their restrained efforts and had more eating disorder behaviours, such as binging (12). If we add the fact that high-calorie foods are more often chosen during such moments, such results may indicate an increased risk among these girls for the development of overweight and obesity in the future (13). Additionally, people who cope with negative emotions by increasing their food intake may later have a higher number of symptoms of eating disorders (14). Girls are more likely to limit their food portions and are more likely to eat less than they would truly like to. Such results are not surprising if we consider that girls are the ones who experience higher levels of social pressure regarding how their body should look like to be ideal (skinny, slim...), and then internalize that ideal more often. This can lead to dissatisfaction with their appearance and result in a variety of unhealthy 
...), te stoga češće internaliziraju te ideale. Sve to može dovesti djevojke do nezadovoljstva vlastitim tijelom, što nadalje rezultira nizom vrlo nezdravih obrazaca hranjenja u cilju gubitka težine. Dobiveni su rezultati jasno pokazali da djevojke imaju više simptoma poremećaja hranjenja u usporedbi s mladićima, što je u skladu s brojnim ranije provedenim istraživanjima (npr. 15).

Treći se dobiveni nalaz odnosi na povezanost između hranjenja i emocija kod različitih skupina prema ITM-u. Adolescenti s preuhranjenošću i pretilošću pokazuju više rezultate u mjerama psihopatologije hranjenja. Pretili su adolescenti zabrinutiji hranjenjem nego njihovi vršnjaci čija je težina u zdravom rasponu, ali su također i zabrinutiji oblikom svojega tijela i svojom težinom u usporedbi s normalno teškim i preuhranjenim adolescentima (oni češće jedu u tajnosti, osjećaju krivnju tijekom obroka, boje se gubitka kontrole tijekom konzumiranja hrane, itd.). Ako se prisjetimo sociokulturnog ideala tjelesnog izgleda, socijalnog pritiska, te stigmatizacije kojoj su izložene osobe povišene tjelesne mase, ne začuđuje da se osjećaju nezadovoljno vlastitom težinom i oblikom tijela, da osjećaju nelagodu pred drugim ljudima te da koriste različite načine ne bi li smanjili svoju težinu, kao što je pokušaj praćenja strogih dijetnih režima, izbjegavanje nekih namirnica, izgladnjivanje, namjerno suzdržavanje od uzimanja hrane itd. (16). Ipak je, suprotno našim očekivanjima, dobiveno da su preuhranjeni i pretili adolescenti jednako skloni jedenju nakon percipiranja negativnih emocija te učestalom doživljavanju gladi i prejedanju, kao i adolescenti čija je težina u zdravom težinskom rasponu. Moguće objašnjenje ovih rezultata možemo potražiti u dobi naših sudionika. Postoji mogućnost da su učinci učestaloga osjećaja gladi i sklonosti ka prejedanju vidljivi na tjelesnoj težini tek tijekom kasnije životne dobi, a ne tijekom adolescencije (17). Osim toga, ponašanja adolescenata u vezi $s$ hranjenjem obilježena su razdobljima gubitka eating patterns with the goal of losing weight. The results obtained here showed that girls have more symptoms of eating disorders than boys, which is consistent with numerous studies (e. g. 15).

The third finding concerns the relationship between eating and emotion in different BMI categories. Adolescents with overweight or obesity showed higher scores in eating disorder psychopathology. Adolescents with obesity are more concerned about eating than healthy weight subjects, but they are also more concerned about their shape and weight than healthy weight and overweight adolescents (they will more frequently eat in secret, feel guilty during meals, have a fear of losing control during meals, etc.). Given the existing sociocultural ideals of physical appearance, social pressure, and the stigma people with excess weight are exposed to, it does not seem unusual for them to be dissatisfied with their weight and body shape, feel uncomfortable in front of other people and try to lose weight in different ways, such as by following certain dietary rules, exclusion of certain food, attempts to fast, intentional restriction of eating, etc. (16). However, contrary to expectations, in regard to eating after experiencing negative emotions and frequent feelings of hunger and overeating, adolescents with overweight and obesity are just as equally prone to eating as healthy weight adolescents. One possible explanation for such findings lies in the age of our respondents. It is possible that the frequent feelings of hunger and the tendency to overeat affect body weight only during older ages and not during adolescence (17). In addition, adolescents' eating behaviours are characterized by periods of loss of control when they tend to binge and are unable to stop, regardless of the adolescents' weight (18).

This study presents some limitations. First, the cross-sectional study design does not permit us to evaluate any causal inference between 
kontrole u kojima su skloni prejedanju, bez mogućnosti zaustavljanja, neovisno o tome koja je njihova tjelesna masa (18).

Ovo istraživanje ima neka ograničenja koja je potrebno naglasiti. Prije svega, transverzalna priroda istraživanja ne dozvoljava nam provjeru kauzalnosti između psihopatologije poremećaja hranjenja i ITM-a. Drugo, korištenje upitnika samoprocjene u cilju ispitivanja odstupajućih obrazaca hranjenja, umjesto korištenja polustrukturiranih intervjua, zasigurno kvalitativno ograničava naše nalaze. Problem socijalne poželjnosti odgovora također je moguće ograničenje ovog istraživanja. Iako se radilo o anonimnom istraživanju, učenici su proveli i kratak intervju s liječnikom školske medicine što je moglo dovesti do potrebe za prikazivanjem u pozitivnijem svjetlu, prešućivanjem nekih informacija. No, istraživanje ima i svoje jake strane. Posebno je važno naglasiti da su podatci o ITM-u izračunati temeljem objektivno izmjerene visine i težine svakoga sudionika u liječničkoj ordinaciji. S druge strane, uključili smo veliki uzorak adolescenata iz PGŽ-a, što znači da se rezultati mogu generalizirati na adolescente prvih razreda srednje škole širom Hrvatske.

Zaključno, naše istraživanje pokazuje da su težina tijela, kognitivno suzdržavanje i nekontrolirano jedenje međusobno povezani kod hrvatskih adolescenata. Povezanost ovih varijabli, koja je replicirana u prospektivnim istraživanjima rizičnih čimbenika razvoja poremećaja hranjenja različitih kohorti u drugim zemljama, trebala bi pomoći u postavljanju ciljeva za intervencije u programima prevencije poremećaja prehrane među adolescentima.

\section{Financiranje}

Ovaj je rad u potpunosti financiran od strane Sveučilišta u Rijeci pod brojem projekta uniri-drustv-18-63: Rizični i zaštitni čimbenici u razvoju povišene tjelesne težine i pretilosti u adolescenciji eating disorder psychopathology and BMI.

Second, the use of self-report instruments to evaluate eating disorder features, instead of semistructured interviews, could limit the quality of our findings. The problem of the answer's social desirability is also a possible limitation of this research. Although it was an anonymous survey, the students also conducted a brief interview with a school physician which could have led to the need to present it in a more positive light, withholding some information. However, this study has some strengths. In particular, the BMI data were calculated based on objectively measured height and weight in the doctor's office. Moreover, we included a large proportion of adolescents with PGKC, and our data could be generalized to adolescents in first-grade high school across Croatia.

In conclusion, our findings indicated that body weight, cognitive restraint and uncontrolled eating are correlated in Croatian adolescents. The association among these variables, replicated in prospective cohort studies investigating risk factors for eating disorders in other countries, should provide some targets for interventions for eating disorder prevention programs among adolescents.

\section{Funding}

This work has been fully supported by the University of Rijeka under the project number uniri-drustv-18-63: Risk and Protective Factors in the Development of Excessive Weight and Obesity in Adolescence

\section{Conflicts of interest/Competing interests}

On behalf of all authors, the corresponding author states that there is no conflict of interest to declare that are relevant to the content of this article. Data are available upon request. 


\section{Sukobi interesa/Konkurentni interesi}

U ime svih autora, autor za prepisku izjavljuje da ne postoji sukob interesa koji bi se mogao proglasiti relevantnim za sadržaj ovoga članka. Podatci su dostupni na zahtjev.

\section{Etičko odobrenje}

Cijeli je postupak istraživanja bio u skladu s etičkim standardima institucionalnog istraživačkog povjerenstva, međunarodnim standardima te s Helsinškom deklaracijom iz 1964. godine i njezinim kasnijim izmjenama, a odobrilo ga je Etičko povjerenstvo za istraživanja Nastavnoga zavoda za javno zdravstvo Primorsko-goranske županije (PGŽ) i Etičko povjerenstvo Sveučilišta u Rijeci tijekom procesa evaluacije projekta.

\section{Ethics approval}

All procedure was in accordance with the ethical standards of the institutional research committee, the international standards and with the 1964 Helsinki Declaration and its later amendments, and it was approved by the Research Ethical Committee of the Teaching Institute for Public Health of Primorje-Gorski Kotar County (PGKC) and of the Ethical Committee of University of Rijeka during the process of Project evaluation.

\section{Informed consent}

Written informed consent was obtained from all legal guardians and participants, before the data collection (parents and students).

\section{Informirani pristanak}

Pisani informirani pristanak pribavljen je od svih zakonskih skrbnika i sudionika, prije prikupljanja podataka (roditelji i učenici).

\section{LITERATURA / REFERENCES}

1. Hooper L, Puhl R, Eisenberg ME, Crow S, Neumark-Sztainer D. Weight teasing experienced during adolescence and young adulthood: Cross-sectional and longitudinal associations with disordered eating behaviours in an ethnically/racially and socioeconomically diverse sample. Int J Eat Disord 2021; 34(8) 1449-82.

2. Urquhart CS, Mihalynuk T V. Disordered eating in women: implications for the obesity pandemic. Can J Diet Pract Res 2011; 72(1):e 115-25.

3. Goldschmidt AB, Aspen VP, Sinton MM, Tanofsky-Kraff M, Wilfley DE. Disordered eating attitudes and behaviors in overweight youth. Obesity 2008; 16(2): 257-64.

4. Dellava JE, Thornton LM, Hamer RM, Strober M, Plotnicov K, Klump KL, Bulik CM et al. Childhood anxiety associated with low BMI in women with anorexia nervosa. Behav Res Ther 2010; 48(1): 60-7.

5. Inchley JC, Stevens GWJM, Samdal O, Currie DB. Enhancing understanding of adolescent health and well-being: The health behaviour in school-aged children study. J Adolesc Health 2020; 66(6): 3-5.

6. Zaborskis A, Petronyte G, Sumskas L, Kuzman M, lannotti RJ. Body image and weight control among adolescents in Lithuania, Croatia, and the United States in the context of global obesity. Croat Med J 2008; 49(2): 233-42.

7. Dzielska A, Kelly C, Ojala K et al. Weight reduction behaviors among european adolescents_Changes from 2001/2002 to 2017/2018. J Adolesc Health 2020; 66(6): S70-80.

8. Fairburn CG, Beglin SJ. Eating Disorder Examination Questionnaire (6.0). In: Fairburn CG (ed.), Cognitive behaviour therapy and Eating Disorders. New York: Guilford Press, 2008, p.309.

9. Hajsok A. Depresivni simptomi, sram i krivnja zbog tjelesne težine u pretilih ljudi. University of Rijeka. Faculty of Humanities and Social Sciences. Department of Psychology, 2017.

10. Barbarić L. Uloga emocionalne regulacije, samoefikasnosti i depresivnih simptoma u objašnjenju prehrambenih navika studenata. University of Rijeka. Faculty of Humanities and Social Sciences. Department of Psychology, 2019.

11. Inchley J, Currie D, Budisavljevic S, Torsheim T, Jastad A, Cosma A, Kelly C et al. Spotlight on adolescent health and well-being. Findings from the 2017/2018 Health Behaviour in School-aged Children (HBSC) survey in Europe and Canada. International Report. Volume 1. Key findings 
12. Van Strien T. The concurrent validity of a classification of dieters with low versus high susceptibility toward failure of restraint. Addict Behav 1997; 22(5): 587-97.

13. Aparicio E, Canals J, Arija V, De Henauw S, Michels N. The role of emotion regulation in childhood obesity: implications for prevention and treatment. Nutr Res Rev 2016; 29(1): 17-29.

14. Stojek MMK, Tanofsky-Kraff M, Shomaker LB, Kelly NR, Thompson KA, Mehari RD, et al. Associations of adolescent emotional and loss of control eating with 1-year changes in disordered eating, weight, and adiposity. Int J Eat Disord 2017; 50(5): 551-60.

15. White HJ, Haycraft E, Goodwin H, Meyer C. Eating disorder examination questionnaire: Factor structure for adolescent girls and boys. Int J Eat Disord 2014; 47(1): 99-104.

16. Putterman E, Linden W. Cognitive dietary restraint and cortisol: importance of pervasive concerns with appearance. Appetite 2006; 47(1): 64-76.

17. Anglé S, Engblom J, Eriksson T, Kautiainen S, Saha M-T, Lindfors P et al. Three factor eating questionnaire-R18 as a measure of cognitive restraint, uncontrolled eating and emotional eating in a sample of young Finnish females. Int J Behav Nutr Phys Act 2009; 6(1): 1-7.

18. Megalakaki O, Mouveaux M, Hubin-Gayte M, Wypych L. Body image and cognitive restraint are risk factors for obesity in French adolescents. Eat Weight Disord Anorexia, Bulim Obes 2013; 18(3): 289-95. 